\title{
A NEW AlGaAs/GaAs/InGaAs LASING SWITCH GROWN BY MBE
}

\author{
MING RONG LEE, K. F. YARN* and W. R. CHANG \\ Far East College, Department of Electrical Engineering, \\ Optoelectronic Semiconductor Center, Hsin-Shih, Tainan, \\ Taiwan 744, Republic of China
}

(Received 30 June 2000; In final form 12 July 2000)

\begin{abstract}
A quantum well optoelectronic switch (QWOES) based on regenerative loop of potential barrier lowering resulted from the forward biased pn junction is demonstrated in a $\mathrm{AlGaAs} / \mathrm{GaAs} / \mathrm{InGaAs}$ double heterostructure. Excellent electrical switching characteristics with a high voltage control efficiency $\eta\left(=V_{S} / V_{H}\right)$ of 6.8 have been obtained when the device is operated in the dark. Typical OFF-and ON-state resistances are $120 \mathrm{k} \Omega$, $25 \Omega$, respectively. A lasing threshold current density, front slope efficiency and external differential quantum efficiency measured in as-cleaved device are $210 \mathrm{~A} / \mathrm{cm}, 0.4 \mathrm{~mW} / \mathrm{mA}$ and $31.4 \%$, respectively. The peak emission wavelength is centered at about $974 \mathrm{~nm}$.
\end{abstract}

Keywords: Quantum well optoelectronic switch (QWOES); Front slope efficiency; Quantum efficiency

\section{INTRODUCTION}

Electrical- and optical-induced negative differential resistance (NDR) switching characteristics in III-V semiconductor devices have found applications in a variety of areas such as microwave generation and high frequency oscillation. Of particular interest is the development of S-shaped NDR devices, including metal-insulator-semiconductor [1], pn junction [2], and delta-doped superlattice [3] devices, in which they have high speed feature. But, most of them are all concentrated on the investigation of electrical properties.

*Address for correspondence: P. O. Box 345, Tainan, Taiwan 704, Republic of China. Fax: 886-6-2022377. 
Recently, double heterostructure optoelectronic switches (DOES) have been developed in GaAs/AlGaAs [4], Si/SiGe [5] and InP/ InGaAsP [6] material structures which are all mainly based on an inversion charge sheet at the internal heterojunction interface. The combination of both electrical and optical switching properties has become a promising feature for optoelectronic integration [7]. For a DOES constructed by a direct band-gap material system, the impedance is high and there is no emission of light in OFF-state, however, the impedance is low and strong emission of light occurs in ON-state. The switching phenomenon between two states could be induced by either electrical or optical triggering.

In this work, a new GaAs/InGaAs single quantum well DOES, i.e., QWOES prepared by molecular beam epitaxy (MBE) has been fabricated. The optical thyristor essentially combines the triangular barrier switch and single quantum well (QW) GaAs/InGaAs structure into a DOES. The use of the strained InGaAs layer offer the potential of a lower threshold current when lasing [8], the light electron-hole mass and higher mobility than those of $\mathrm{GaAs} \mathrm{QW}$ structures. To our knowledge, the QWOES is the first switching device reported to date for $\mathrm{GaAs} / \mathrm{InGaAs}$ material system with a lasing operation in switching ON-state.

\section{EXPERIMENTAL}

The schematic cross section of the QWOES is depicted in Figure 1(a). The studied structure was grown by MBE on a (100)-oriented $\mathrm{n}^{+}$-GaAs substrate. Si and Be were used as $\mathrm{n}$ - and p-type dopants, respectively. This structure contained a $0.5 \mu \mathrm{m}$-thick $\left(\mathrm{n}^{+}=2 \times\right.$ $\left.10^{18} \mathrm{~cm}^{-3}\right)$ GaAs buffer layer, a $0.15 \mu$ m-thick $\left(\mathrm{n}^{+}=2 \times 10^{18} \mathrm{~cm}^{-3}\right)$ $\mathrm{Al}_{0.4} \mathrm{Ga}_{0.6} \mathrm{As}$ barrier layer, a $5 \mathrm{~nm}$-thick $\left(\mathrm{p}^{+}=1 \times 10^{19} \mathrm{~cm}^{-3}\right)$ $\mathrm{Al}_{0.4} \mathrm{Ga}_{0.6} \mathrm{As}$ charge sheet layer, a $15 \mathrm{~nm}$-thick undoped $\mathrm{In}_{0.2} \mathrm{Ga}_{0.8} \mathrm{As}$ QW sandwiched with two $10 \mathrm{~nm}$-thick undoped GaAs layers, a $0.08 \mu \mathrm{m}$-thick $\left(\mathrm{n}=1 \times 10^{17} \mathrm{~cm}^{-3}\right) \mathrm{GaAs}$ collector layer, a $0.15 \mu \mathrm{m}$ thick $\left(\mathrm{p}^{+}=1 \times 10^{18} \mathrm{~cm}^{-3}\right) \mathrm{Al}_{0.4} \mathrm{Ga}_{0.6}$ As barrier layer and a $0.2 \mu \mathrm{m}$ thick $\left(\mathrm{p}^{+}=1 \times 10^{19} \mathrm{~cm}^{-3}\right) \mathrm{GaAs}$ cap layer. For fabricating a broad area laser, the $\mathrm{p}^{+}$-side was metallized with $\mathrm{Au} / \mathrm{Zn}$ and then, the substrate was thinned to a thickness of $\sim 100 \mu \mathrm{m}$. Au/Ge was evaporated 


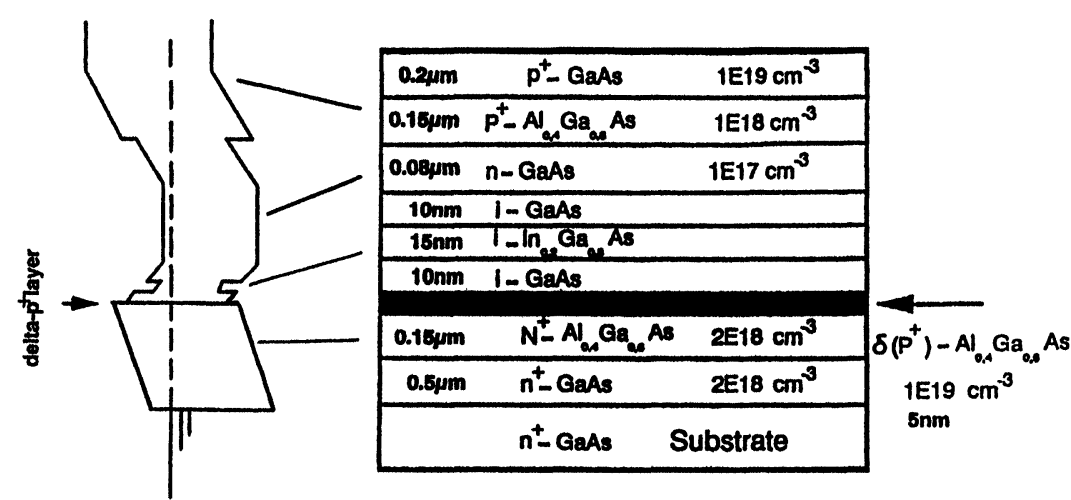

(b)

(a)

FIGURE 1 (a) Schematic cross section of the QWOES (b) Energy band diagram of the QWOES at equilibrium.

on the $\mathrm{n}$-side and the wafer was then alloyed. The area of the laser bar was $150 \mu \mathrm{m} \times 350 \mu \mathrm{m}$ after cleaving. Electrical current-voltage (I-V) characteristics were measured by a Tektronix $370 \mathrm{~A}$ curve tracer at room temperature.

\section{CHARACTERISTICS}

The energy band diagram of the QWOES is illustrated in Figure 1(b). The heterojunction potential barrier and InGaAs QW structure with higher valence band offset are used to improve the localized confinement of the holes. For a DOES, the basic principle of these triangular barrier based switches is that NDR is caused by an increase of hole injection to the potential barrier minimum with an increase in the forward biased pn junction; then the triangular barrier rapidly collapses, leading to a fast switch from a high-impedance OFF-state to a low-impedance $\mathrm{ON}$-state. The experimental $\mathrm{I}-\mathrm{V}$ characteristic at room temperature is shown in Figure 2. The measured switching parameters of the QWOES at room temperature are switching voltage $\mathrm{V}_{S}=11 \mathrm{~V}$, switching current $I_{S}=0.5 \mathrm{~mA}$, holding voltage $\mathrm{V}_{H}=1.6 \mathrm{~V}$ and holding current $I_{H}=4.5 \mathrm{~mA}$, respectively. $\mathrm{I}-\mathrm{V}$ characteristics in $\mathrm{ON}$-state are all independent of external voltage due to inherent properties of pn junctions. The resistance in OFF-state is typically 


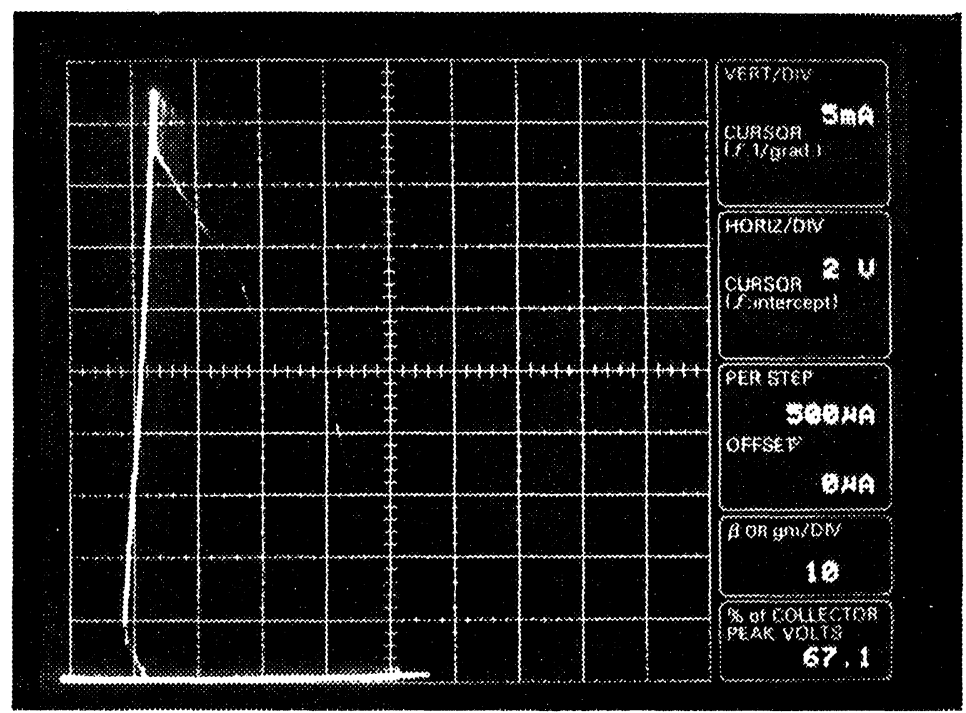

FIGURE 2 Room temperature I-V characteristic of the QWOES.

greater than $120 \mathrm{~K} \Omega$ and the ON-state resistance is lower than $25 \Omega$. The observed switching and holding voltage lead to a high voltage control efficiency, $\eta_{v}\left(=\mathrm{V}_{S} / \mathrm{V}_{H}\right)$, of 6.8. This voltage control efficiency is among the largest reported so far in a field represented by DOES [4-6].

The optical characteristics of the as-cleaved lasing QWOES were measured under pulsed condition at room temperature. In the case of pulsed operation, the pulse width was $50 \mu \mathrm{s}$ with a repetition rate of $1 \mathrm{KHZ}$. Figure 3 shows the pulsed power output versus current and spectrum (inset) measured at a bias current equal to the threshold current. The threshold current $I_{t h}$ was measured to be $110 \mathrm{~mA}$, with a front slope efficiency of $0.4(\mathrm{~mW} / \mathrm{mA})$, and yielded $14 \mathrm{~mW}$, at a current of $134 \mathrm{~mA}$. The external differential quantum efficiency is as high as $31.4 \%$. Although the $I_{t h}$ is large, it is the first experimental realization of a lasing device in GaAs/InGaAs-based DOES. Hence, it is pointed out that this device has not been optimized, better laser cavity geometries are expected to allow the decrease of $I_{t h}$. In addition, the spectrum of the optical output is also shown in the inset of Figure 3, at a current $I=I_{t h}$. As can be seen, the QWOES lases at an emission 


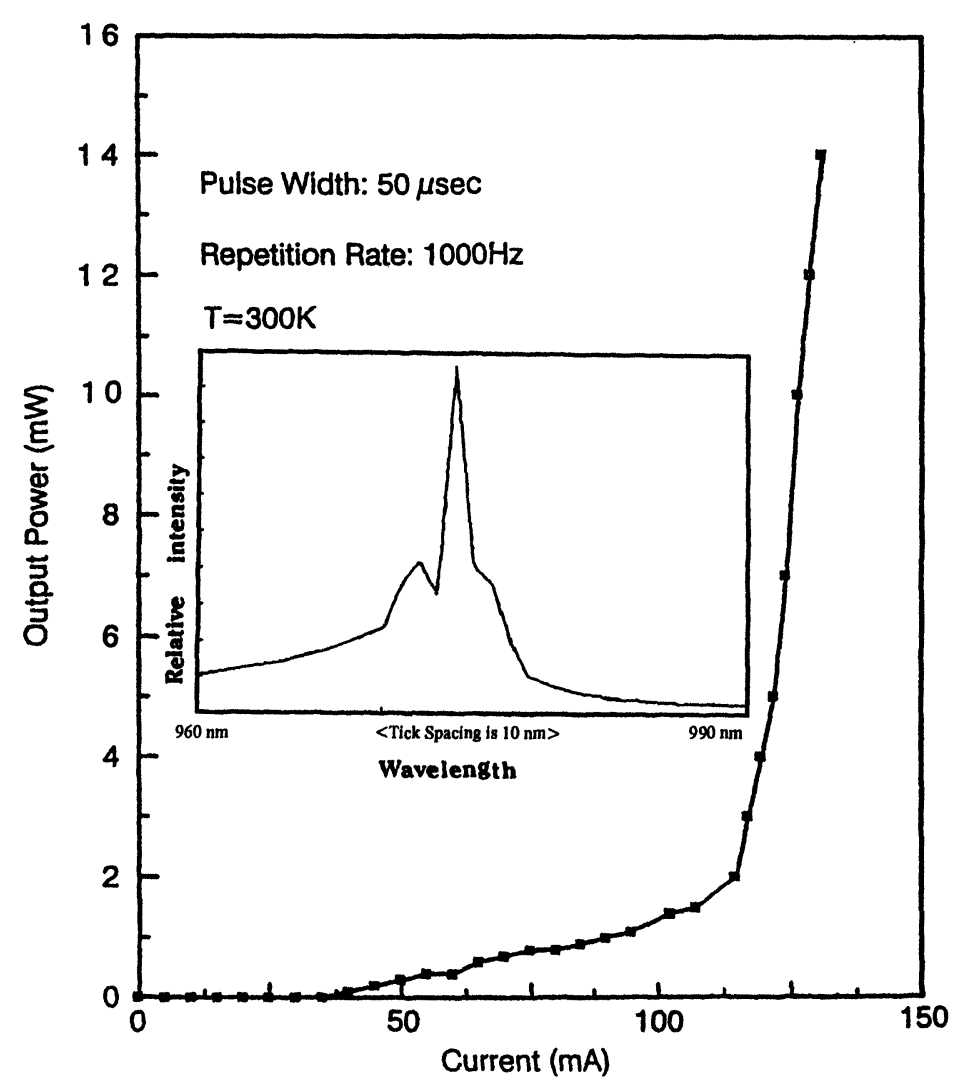

FIGURE 3 Pulsed power output versus current and emission spectrum (in the inset) measured at a bias current $I=I_{t h}$.

wavelength about $974 \mathrm{~nm}$ with a spectrum full width at half maximum (FWHM) of $1 \mathrm{~nm}$.

\section{CONCLUSIONS}

We have successfully exploited for the first time an InGaAs QW infrared laser diode operating at a wavelength of $974 \mathrm{~nm}$ on switching using $\mathrm{AlGaAs} / \mathrm{GaAs} / \mathrm{InGaAs}$ double heterostructure. The lasing threshold current is $110 \mathrm{~mA}$, corresponding to a current density of $210 \mathrm{~A} / \mathrm{cm}^{2}$, and the external differential quantum efficiency is $31.4 \%$ at 
room temperature. I-V switching characteristics are excellent and reproducible with a high voltage control efficiency of 6.8 . The inherent properties of electrical bi-stability and laser emission suggest the possibility of the QWOES for optoelectronic applications.

\section{References}

[1] Yamamoto, T. and Morimoto, M. (1972). 'Thin-MIS-structure Si negativeresistance diode', Appl. Phys. Lett., 20, 269-270.

[2] Wood, C. E. C., Eastman, L. F., Board, K., Singer, K. and Malik, R. J. (1982). 'Regenerative switching devices using MBE-grown gallium arsenide', Electron. Lett., 18, 676-677.

[3] Schubert, E. F., Cunningham, J. E. and Tsang, W. T. (1987). 'Perpendicular electronic transport in doping superlattices', Appl. Phys. Lett., 51, 817-819.

[4] Taylor, G. W., Simmons, J. G., Cho, A. Y. and Mand, R. S. (1986). 'A new double heterostructure opto-electronic switching device using molecular beam epitaxy', J. Appl. Phys., 59, 596-598.

[5] Kovacic, S. J., Simmons, J. G., Song, K., Noel, J. P. and Houghton, D. C. (1991). 'Si/SiGe digital optoelectronic switch', IEEE Electron Device Lett., EDL-12, 439-441.

[6] Kovacic, S. J., Robinson, B. J., Simmons, J. G. and Thompson, D. A. (1993). 'InP/ InGaAsP double-heterostructure optoelectronic switch', IEEE Electron Device Lett., EDL-14, 54-56.

[7] Simmons, J. G. and Mand, R. S. (1991). 'Characteristics and applications of digital opto-electronic switches (DOES)', Asia-Pacific Eng. J., 1A, 59-88.

[8] Corzine, S. W., Yan, R. H. and Coldren, L. A. (1990). 'Theoretical gain in strained InGaAs/GaAs quantum wells including valence-band mixing effects', Appl. Phys. Lett., 57, 2835-2838. 

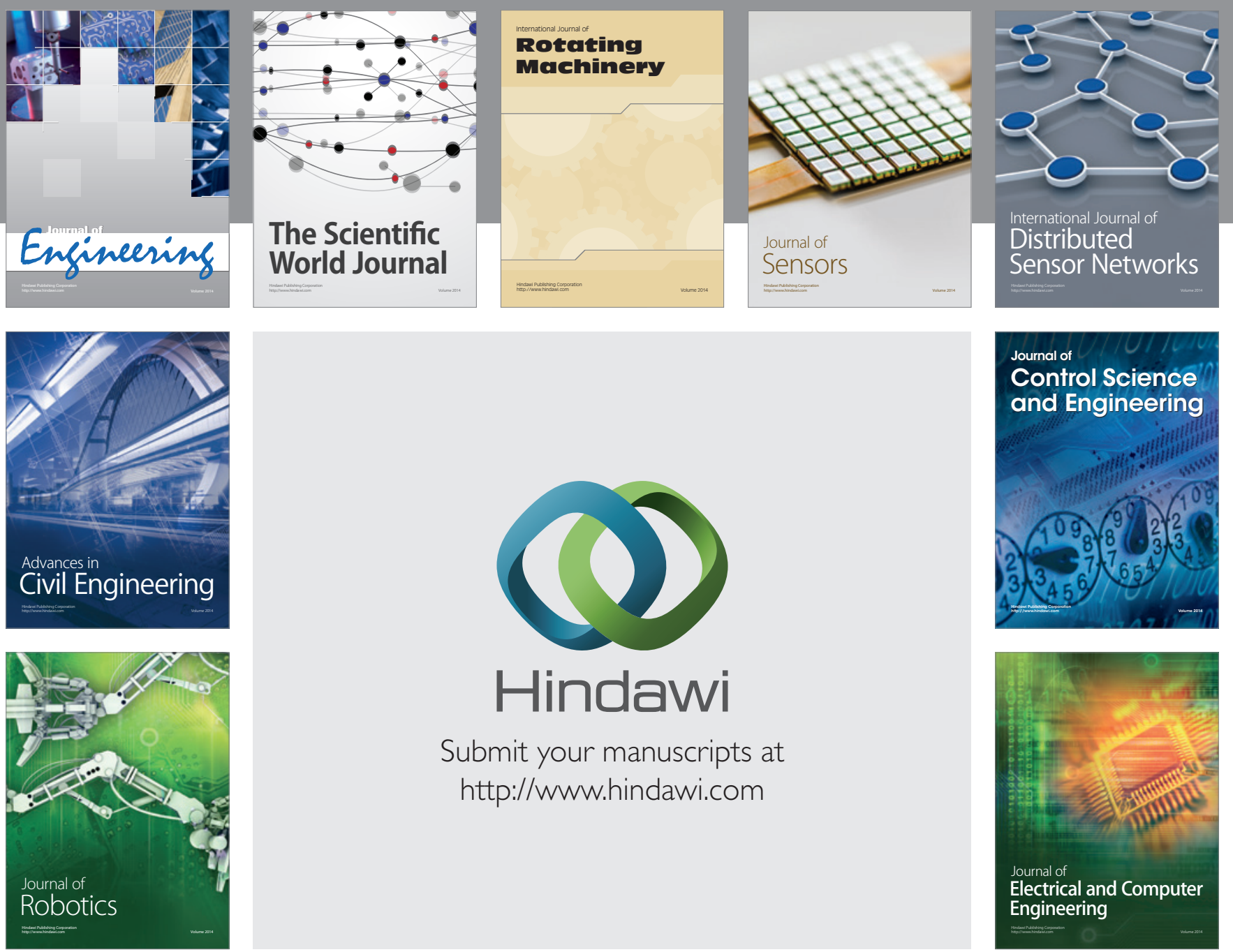

Submit your manuscripts at

http://www.hindawi.com
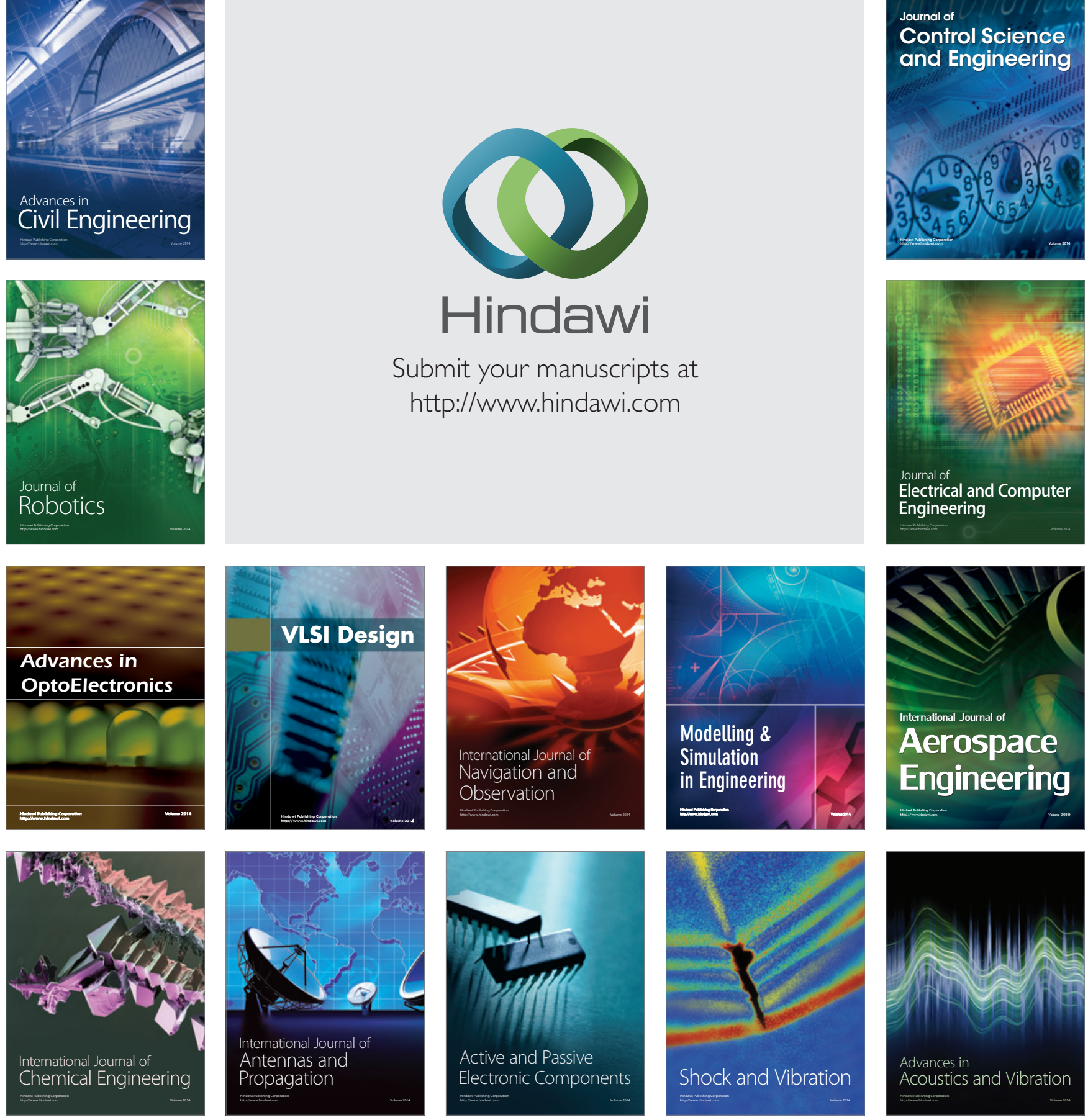